\title{
Nondestructive Evaluation of the Defects in Composite-sintered Bushes Using Ultrasonics
}

\author{
Kwang-Hee Im, Ki-Youl Kim¹, Ki-Taek Shin1, Han-Hee Lee1, Il-Woong Jung1, To Kang², and Hyun-Joon Cho² \\ \# Dept. of Auto. Eng., Woosuk University, 490, Samrae-up, Wanju-kun, Chonbuk, 565-701, Korea \\ 1 R\&D Team, TMC Co. Ltd. 750-1 Palbok-dong 2ga, Dukjin-ku, Jeonju, Chinbuk, 561-844, Korea \\ 2 R\&D Team, AIQS Co. Ltd. 503 Worldvision, 234-6 Kochon Weuwang, Kunggi, 437-801, Korea \\ \# Corresponding Author / E-mail: khim@woosuk.ac.kr, TEL: +82+63-290-1473 , FAX: +82+63-291-9312 \\ (Manuscript received: Oct, 10, 2012 / Revised: Nov, 15, 2012 / Accepted: Nov, 27, 2012)
}

\begin{abstract}
Advanced composite-sintered bushings are widely utilized in the areas of excavators and injection molding machines as a journal bearing. Since the bearings are mainly used under high loads, service life should be long and the stored oil of inner bushings has to be continually fed into the bearing. The composite-sintered bushings are consisted of the two different materials; outer steel materials and inner porous sintered materials respectively. High temperature diffusion bonding has been applied for holding the both materials of the bushing together. Therefore, it is very important that the bonding reliability has to be assured and evaluated in manufacturing process. Finite element method (FEM) is performed in order to evaluate the minimum allowable flaw sizes that are possibly generated in the composite-sintered bushings. Additionally, the composite-sintered bushings were undergone ultrasonic C-scan tests to find out the size of inherent flaws through artificially simulated UT signal analysis.
\end{abstract}

\section{Introduction}

The bushes are ones of machine and automobile parts like brake used in drums and hubs in particular. Such bush parts are used for bearings of heavy-duty, large cars requiring wear resistance and high load carrying capacity.

Sintering technology used in the composite sintered bushings has brought dramatically improved core components. Joints are composed of more than 30 tons excavator, loader and heavy duty / high-shock heavy-duty bearings ${ }^{(1)}$.

Composite sintered bushing ${ }^{(2-4)}$ for use in heavy-duty purpose has been developed by domestic engineers since 2000. Only H-company and TMC Co. Ltd are currently making various types of bushings that can be used for practical purpose.

Highly advanced composite-sintered bushings are widely utilized in the areas of excavators and injection molding machines as a journal bearing. Since the bearings are mainly used under high loads, service life should be long and the stored oil of inner bushings has to be fed continually into the bearing ${ }^{(5 \sim 6)}$. The composite-sintered bushings are consisted of two different materials; outer steel material and inner porous sintered body respectively. High temperature diffusion bonding has been applied for bonding the both materials of the bushing together. Also, the sintering process affects to the change into high capacity, excellent high temperature strength, impact resistance, elongation at break and friction and wear characteristics of the products.

However, performance acceptance / reject depends on the ultrasound A-scan peak signals ${ }^{(2)}$ in the detection of defects. There are many cases in the field not falls on acceptance criteria based on fracture mechanics. In many cases, rejecting is done only by experienced level of defects regardless of on-axis direction (circumferential direction), even if the small defect level won't influence the actual failure.

Level of user demand is very high, and a high level of quality assurance is required in many cases. Also, high-performance low-cost processing for evaluating defect with fast and accurate assessment is required. Criteria of reasonable level based on objective data and diagnostic system is really needed. Therefore, it is very important that the bonding reliability has to be assured and evaluated in manufacturing process. The non-destructive inspection / evaluation (NDE) ${ }^{(2)}$ is utilized for this purpose with reinforcement of FEM simulation. Quality assurance criteria will be defined for composite-sintered bushing and the ultrasound diagnostic assessment system will be developed.

\section{Principle of Bushes}

\subsection{Principle of Operation}

The sintered bushing made of steel and copper powder has approximately $18-23 \%$ pores inside inherently. At this time, oil is 


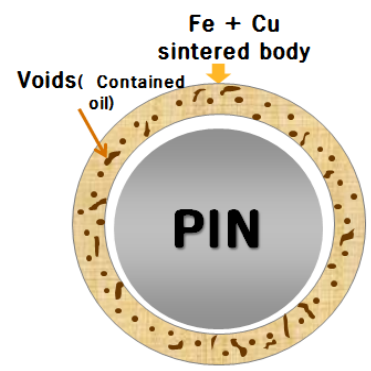

(a) Before turning

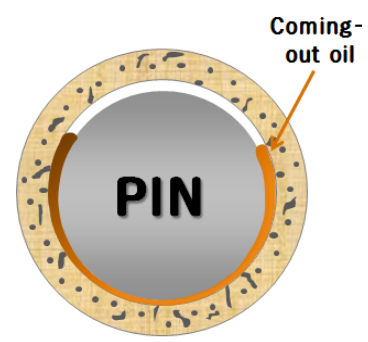

(b) After turning

Fig. 1 Diagram showing the oil movement between steel and composite-sintered bush

soaked into the pores of the sintered body. (See Fig. 1(a)). A reciprocal right and left angle movement of the pin used in the excavator causes rise of pressure and temperature ${ }^{(1)}$. At this time, the soaked oil inside the pore flows out into the gap between the pin and bush as shown in Fig. 1(b) giving lubricating action.

\subsection{Processing Method}

The composite-sintered bushing is composed of steel outside and porous sintered body inside, and the two (2) different materials are bonded together by high temperature diffusion bonding method. Reliability of the bond is important factor more than anything else in determining the quality of the product. Ultrasonic waves are utilized in total acceptance inspection. The manufacturing process of the composite-sintered busing is composed in the following 8 processes; starting from the molding process after sufficient mixing of powder,

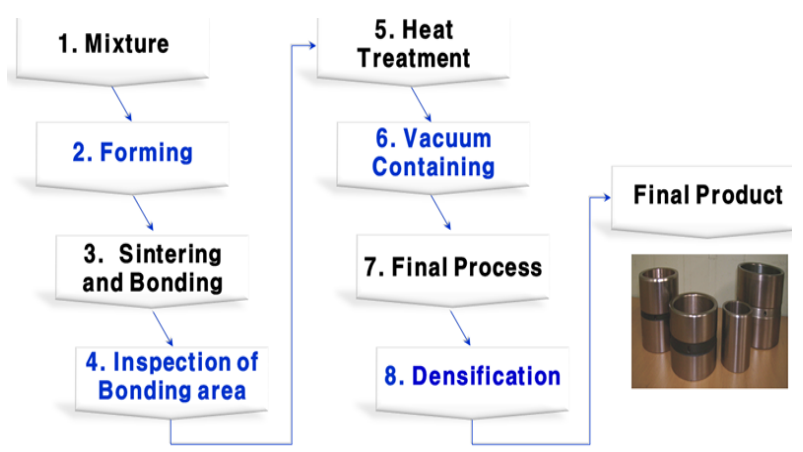

Fig. 2 Processing procedures for bushings

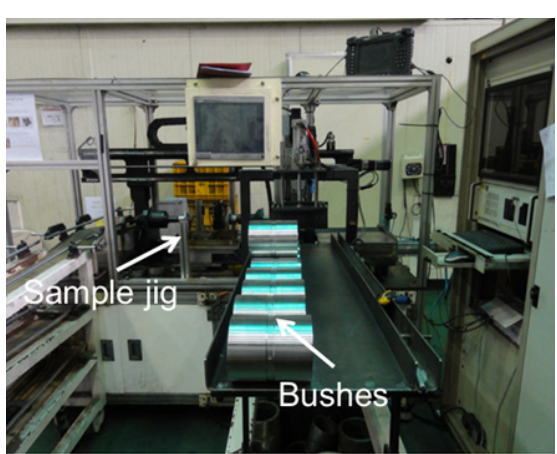

(a) Photo of C-scanner

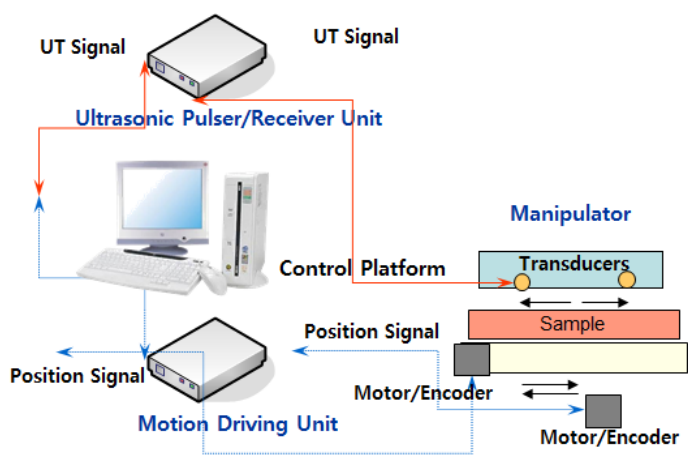

(b) Schematic diagram of C-scanner

Fig. 3 Photo and schematic diagram for ultrasonic system

sintering process that sinters hard the molded work, fitting process that push fits the sintered body into the steel pipe, the bonding process that bonds the sintered body with the steel pipe together by heat treatment, heat treatment process for heightening surface hardness and finally, finish process and oil soaking.

\section{Experimental System Measuring and Simulation}

\subsection{Non-Destructive Evaluation System}

Photo and schematic diagram for transducer position in pulse-echo mode using the motorized scanner is shown in Fig. 3. Two 5MHz, $12.7 \mathrm{~mm}$ in diameter longitudinal wave transducers in pulse -echo mode were used because two sides of the bushes could be scanned at the same time. The two transducers are supported by a holder and samples can be rotated by a stepper motor with a maximum resolution of 0.9 degree. Each time after a full revolution of scan, the scanner reverses to the starting position so that the next scan is ready for another sample. The water couplant in immersion tank is used for the scanning. A peak-to-peak amplitude was taken on the digital oscilloscope during data processing (see Fig. 3 (b)). The system consists of a PC, a pulser-receiver, a motor driver and the immersion probes described above. The waves were generated and received using a pair of Panametrics, $12.7 \mathrm{~mm}$ diameter, $5 \mathrm{MHz}$, longitudinal wave transducers which were coupled to the composite-sintered bushes. 


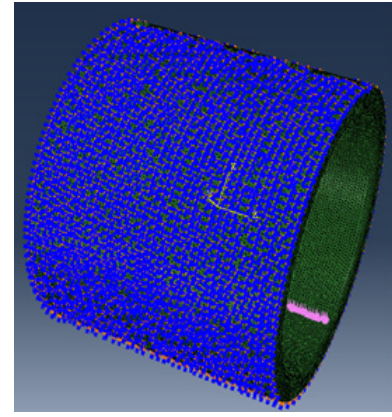

(a) Modeling of bush

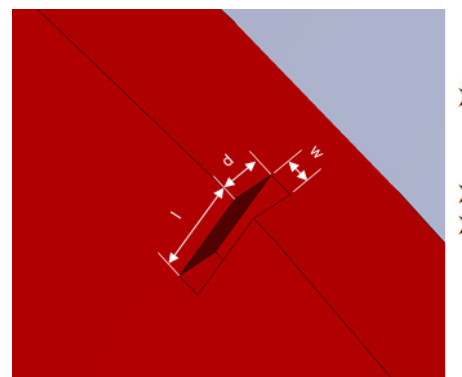

(c) Crack size

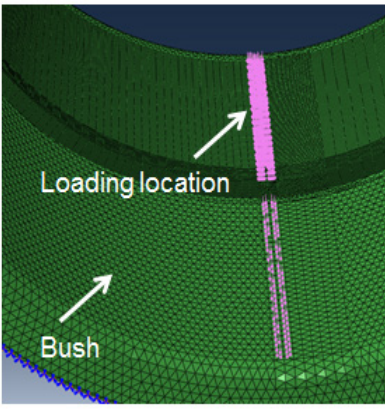

(b) Loading area

> Width of

circumferential

direction(w): $0.5 \mathrm{~mm}$

Depth(d): $0.2 \mathrm{~mm}$

Length of axial

direction:

$0.1,0.5,1,2.5,5 \mathrm{~mm}$

Fig. 4 FEM modeling of the composite-sintered bushes

\subsection{FEM Simulation}

The simulation was performed by FEM ABAQUS (MSC. Co. Ltd.). The composite-sintered bushing is made of steel outer skin with porous sintered body inside and the two (2) different materials are bonded together by high temperature diffusion bonding method. FEM modelling at this time was made by an assumption that there is no deformation in the steel and the composite-sintered bush only causes deformation. Intentional defects of cracks of $0.1 \mathrm{~mm}, 0.5 \mathrm{~mm}$, $1.0 \mathrm{~mm}, 2.5 \mathrm{~mm}$ and $5.0 \mathrm{~mm}$ respectively were fabricated into the body of the bush. Loads were applied at 3 degrees of 1.5 degrees both sides assuming that the pin and bush makes almost linear contact when the excavator is in use. Fig. 4 shows FEM modeling under 6-displacement constraints at all the nodes of the steel. Sizes of cracks are shown in Fig. 4(c). Particularly in this simulation, the lengths of crack only were varied to $0.1 \mathrm{~mm}, 0.5 \mathrm{~mm}, 1.0 \mathrm{~mm}, 2.5 \mathrm{~mm}$ and $5.0 \mathrm{~mm}$ respectively.

Also, the mechanical properties could be obtained in this testing. The relevant parameters used for the steel and composite-sintered bushes are as follow; 1) Young's modulus is $205.8 \mathrm{GPa}$ and tensile strength is $313.6 \mathrm{MPa}$ for steel and 2) Young's modulus is $78.4 \mathrm{MPa}$ and tensile strength is $250 \mathrm{MPa}$ for composite-sintered bushes.

\section{Result \& Discussion}

\subsection{Characteristics of Composite-Sintered Bush}

Composite-sintered bush is one of journal bearings used for high loads like those of excavator and injector. It is required to have long service life and to have oil store inside that supplies lubricating oil

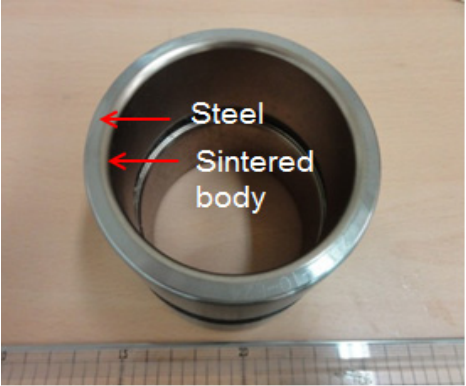

(a) Photo in composite- sintered bush

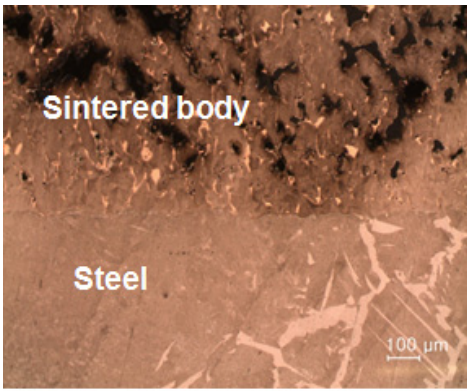

(b) Good joint between sintered body and steel

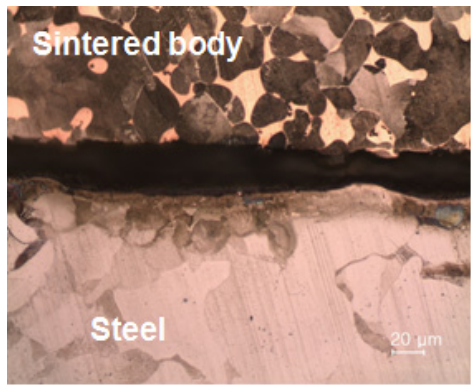

(c) Poor joint between sintered body and steel

Fig. 5 Photo of composite-sintered bush and optical microscopic images of (a) good joint and (b) poor joint between sintered body and steel

continuously. This is one of the advanced new material bearings. At the time of bonding the steel to the composite-sintered bush by high temperature diffusion bonding method, there would cause many phases of bonding condition. Fig. 5(a) shows a completed composite-sintered bush having steel outer skin and sintered body inside. Fig. 5 (b) and (c) show bonded condition of the steel and sintered body. Particularly in Fig. 5(b), it is shown that the sintered body and the steel is bonded tightly without any change. However, in Fig. 5(c), it is shown that there are many changes in the surface, not to mention many cracks between the sintered body and the steel. This is thought that there were poor machining of the steel and the sintered body or effects of load or bonding speed when bonding by high temperature diffusion bonding. It is also thought that voids or defects inside the composite-sintered body may have caused the change, however, it was difficult to make any quantitative evaluation. 


\subsection{Non-Destructive Evaluation of Composite- Sintered Bush}

In designing product manufacturing of composite-sintered bush, it is required to secure material design technology that improves load bearing capability and to secure bonding technology of molded body that contains uniform porosity in certain level and have an oil-less characteristics by shortened sintering process. In order to realize cost reduction in the manufacturing process of composite-sintered bush by shortened sintering process and thus to be competitive in price as well as to be competitive in the price of offshoot products manufactured by other domestic firms, soundness and reliability of the composite-sintered bush is of the highest requirement, and in order to assure the soundness and reliability, pertinent evaluation technique is required. As shown in Fig. 3(a) and (b), the authors have developed non-destructive ultrasonic test system for evaluating the completed product of composite-sintered bush. If there is any defect like crack in the boundary layer between the sintered body and steel skin, high reflective pulse of ultrasonic wave is generated. A steel tube was made

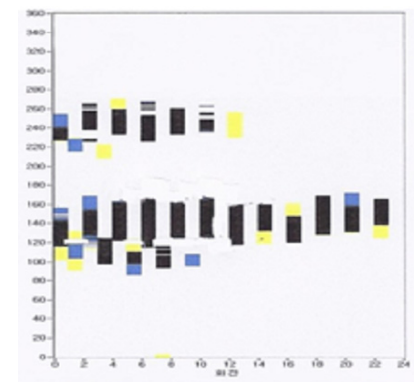

(a) Acceptance

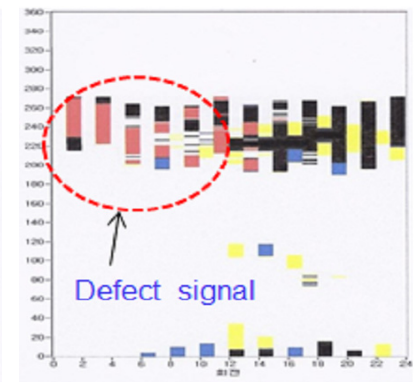

(b) Reject
Fig. 6 Ultrasonic C-scan images of (a) acceptance and (b) reject

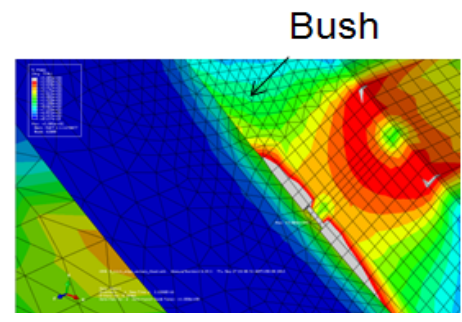

(a) $0.1 \mathrm{~mm}$

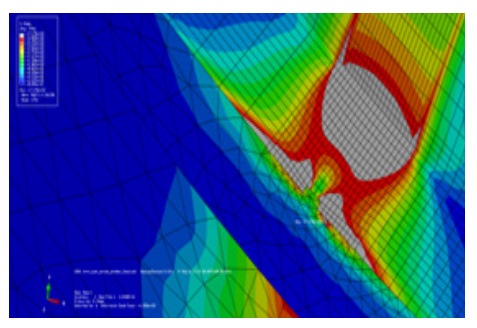

(b) $1 \mathrm{~mm}$

Fig. 7 Simulation of edge cracks with (a) $0.1 \mathrm{~mm}$ and (b) $1.0 \mathrm{~mm}$ in crack length for making a reference signal. so, it was assumed that a defect signal was considered as $100 \%$ of peak-to-peak amplitude when a signal was reflected at the steel. At this time, red color appears when peak-topeak amplitude is $80 \%$ or higher and black with yellow appears when it is lower than that. In Fig. 6(a) and (b), there is no red in Fig. 6 (a) while red appears in Fig. 6 (b) meaning high amplitude there to show it a defect signal and the product to reject.

Therefore, the creative development of shortened manufacturing process for the composite-sintered bush could realize cost reduction and secure an agreeable bonding technology. Further in future, by persistent progress of the bonding molded body, it may provide basic design data for development of piston insert ring that is composed of stainless steel sintered body or development of synchronizer that bonds sintered friction substance to the copper alloy.

\subsection{FEM Simulation}

The FEM modeling technology was utilized based on the analysis methods of Fracture mechanics with using composite-sintered

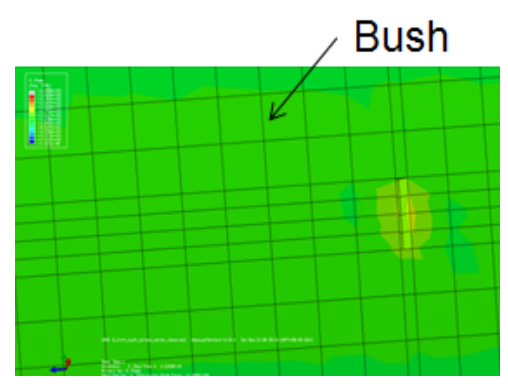

(a) $0.1 \mathrm{~mm}$

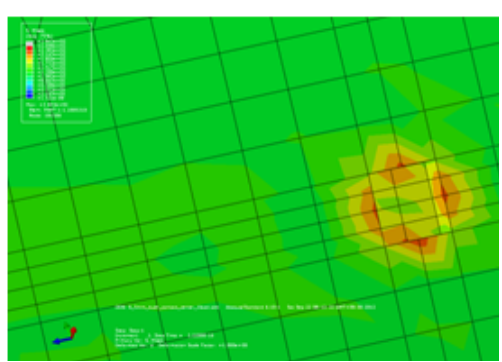

(b) $0.5 \mathrm{~mm}$

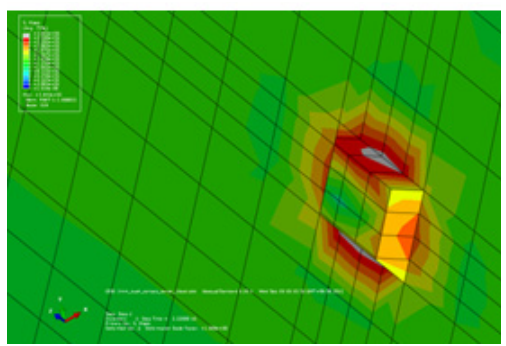

(c) $1.0 \mathrm{~mm}$

Fig. 8 Simulation of inner cracks with (a) $0.1 \mathrm{~mm}$ and (b) $0.5 \mathrm{~mm}$ (c) $1.0 \mathrm{~mm}$ in crack length 


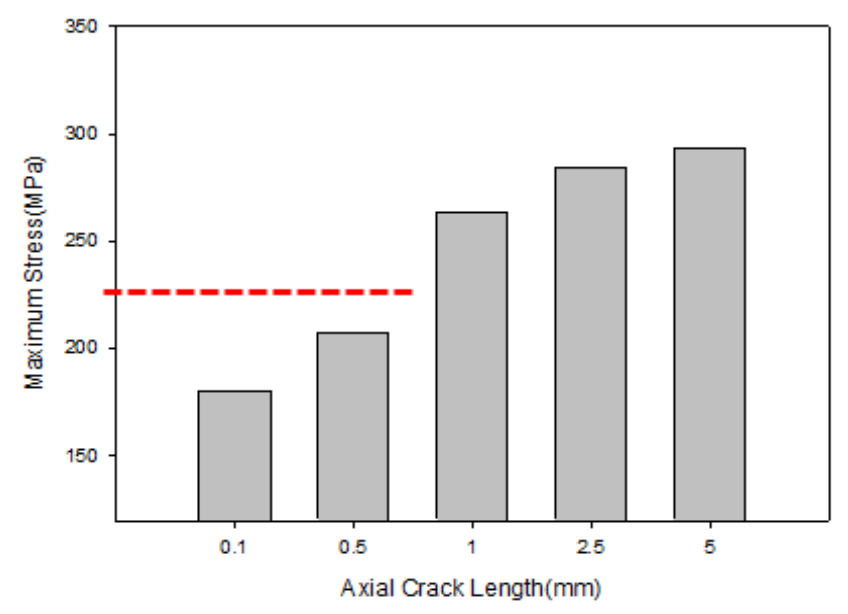

Fig. 9 Comparison between size of inner axial cracks and maximum stress in composite-sintered bused

bushings for the actual defect levels. A reasonable level of this defect could be detected by an ultrasound inspection devices for a use of evaluation algorithms / software developed for the diagnosis of defects possible in the bushes. It was confirmed that manufacturing costs be lower and process improvements be done in order to build infrastructures.

Fig. 7 shows edge cracks fabricated in axial direction. This is the result of simulation of cracks in axial direction having length of $0.1 \mathrm{~mm}$ and $1.0 \mathrm{~mm}$ respectively. Nearby the smallest crack of $0.1 \mathrm{~mm}$ length, there was a defect and maximum stress at this point was shown approximately 430MPa. This was far higher than 250MPa, the tensile strength of bush. This tells that even smallest edge crack may lead to a defect. Contrary to this, Fig. 8 shows the cracks fabricated inside in axial direction, not in the edge. When the length of crack, at this time, was $0.1 \mathrm{~mm}$ and $0.5 \mathrm{~mm}$ respectively in axial direction, there was no deformation while the deformation appeared when the length is $1.0 \mathrm{~mm}$ or longer. Fig. 9 shows relationship between the length of inside crack in axial direction and maximum stress. Within the range of crack length from $0.1 \mathrm{~mm}$ and up to $1.0 \mathrm{~mm}$, it was within the range of tensile strength of the bush. It is thought, therefore, that the cracks below the dotted red line in Fig. 9 are not affecting the compositesintered bush seriously under the same condition.

It could be seen that, in the soundness aspect of composite-sintered bush bonding, the edge crack is more sensitive to deformation than the inside crack. This is thought because one side of the edge crack is open in the slope surface.

\section{Conclusions}

Ultrasonic C-scan tests were applied to the composite-sintered bushes to find out a reasonable level of this defect. Following results could be obtained.
(1) It was thought that defects like crack of a few hundred $\mu \mathrm{m}$ size could be found through optical microscope due to inappropriate manufacturing process.

(2) A ultrasonic C-Scanner was developed for evaluating compositesintered bushes based on accepting level of peak-to-peak value.

(3) It was found that no deformation could be observed in axial direction cracks of $0.1 \mathrm{~mm}$ and $0.5 \mathrm{~mm}$ length which indicates that the location and size of crack have influenced seriously.

\section{ACKNOWLEDGMENTS}

This work was supported by Research Development Project of New Growth Industry (2012) in Jeonbuk R\&D Program through Jeonbuk Technopark.

\section{REFERENCES}

(1) Kim, Y. B., Kim, P. Y., Kim, I. K., Kwon, H. S., Lee, M. H., and Park, J., 2010, “A Study on the Durability Design of a Hydraulic Cylinder for an Excavator," Journal of the KSME, Vol. 34, No. 12, pp. 1901 1907.

(2) Im, K. H., Zhang, G. L., Choi, S. R., Ye, C. H., Ryu, J. S., Lim, S. H., Han, M. G., and Hsu, D. K., 2011, "One-sided Nondestructive Evaluation of CFRP Composites by using Ultrasonic Sound," Journal of the Korean Society of Machine Tool Engineers, Vol 20, No. 1, pp. 47 52.

(3) Habalia, S. M., and Salehb, L. A., 2000, "Local Design, Testing and Manufacturing of Small Mixed Airfoil Wind Turbine Blades of Glass Fber Reinforced Plastics Part I: Design of the Blade and Root," Energy Conversion \& Management, Vol. 41, No. 1, pp. 249 280.

(4) Tse, K. W., Moyer, C. A., and Arajs, S., 1981, "Electrical Conductivity of Graphite Fiber epoxy Resin Composites," Materials Science and Engineering, Vol. 49, No. 1, pp. 41 46.

(5) Kim, K. K., 2007, "SEM/EDX Analysis on the Composition and Surface Defect in a Pin Bushing Bearing for an Automative Engine," Journal of the KSTLE, Vol. 23, No.5, pp. 195 200.

(6) Kwon, K. Y., Chol, S. D., Chenong, S. H., Lee, J. H., and Ham, Y. B., 2003, "A Study on the Bonding of Bush for Piston Pump Cylindar," Conference Journal of KSMPE, Vol. 1, No. 1, pp. 134 138.

(7) Kim, C. K., and Kim, D. H., 2007, "Contact Pressure Distribution of Pin Bushing Bearings Depending on the Friction Conditions," Jounal of the KSTLE, Vol. 23, No. 6, pp. 255 260. 